\title{
A simple method for reducing inevitable dielectric loss in high-permittivity dielectric elastomers
}

Madsen, Frederikke Bahrt; Yu, Liyun; Mazurek, Piotr Stanislaw; Skov, Anne Ladegaard

Published in:

Smart Materials and Structures

Link to article, DOI:

10.1088/0964-1726/25/7/075018

Publication date:

2016

Document Version

Peer reviewed version

Link back to DTU Orbit

Citation (APA):

Madsen, F. B., Yu, L., Mazurek, P. S., \& Skov, A. L. (2016). A simple method for reducing inevitable dielectric loss in high-permittivity dielectric elastomers. Smart Materials and Structures, 25(7), [075018].

https://doi.org/10.1088/0964-1726/25/7/075018

\section{General rights}

Copyright and moral rights for the publications made accessible in the public portal are retained by the authors and/or other copyright owners and it is a condition of accessing publications that users recognise and abide by the legal requirements associated with these rights.

- Users may download and print one copy of any publication from the public portal for the purpose of private study or research.

- You may not further distribute the material or use it for any profit-making activity or commercial gain

- You may freely distribute the URL identifying the publication in the public portal 


\title{
A simple method for reducing inevitable dielectric loss in high- permittivity dielectric elastomers
}

\author{
F. B. Madsen, L. Yu, P. Mazurek and A. L. Skov* \\ Danish Polymer Centre, Department of Chemical and Biochemical Engineering, Technical \\ University of Denmark, DTU, Søltofts Plads, building 227, 2800 Kgs. Lyngby, Denmark \\ E-mail: al@kt.dtu.dk
}

\begin{abstract}
Commercial viability of dielectric elastomers is currently limited by a few obstacles, including high driving voltages (in the $\mathrm{kV}$ range). Driving voltage can be lowered by either decreasing the Young's modulus or increasing the dielectric permittivity of silicone elastomers, or a combination thereof. A decrease in the Young's modulus, however, is often accompanied by a loss in mechanical stability, whereas increases in dielectric permittivity are usually followed by a large increase in dielectric loss followed by a decrease in breakdown strength and thereby the lifetime of the dielectric elastomer. A new soft elastomer matrix, with high dielectric permittivity and a low Young's modulus, aligned with no loss of mechanical stability, was prepared through the use of commercially available chloropropyl-functional silicone oil mixed into a tough commercial LSR silicone elastomer. The addition of chloropropylfunctional silicone oil in concentrations up to $30 \mathrm{phr}$ was found to improve the properties of the silicone elastomer significantly, as dielectric permittivity increased to 4.4, dielectric breakdown increased up to $25 \%$ and dielectric losses were reduced. The chloropropyl-functional silicone oil also decreased the dielectric losses of an elastomer containing dielectric permittivity-enhancing $\mathrm{TiO}_{2}$ fillers. Commercially available chloropropyl-functional silicone oil thus constitutes a facile method for improved silicone dielectric elastomers, with very low dielectric losses.
\end{abstract}

\section{Introduction}

Dielectric elastomers (DEs), consisting of a thin elastomer film sandwiched between compliant electrodes, have many favourable properties such as low weight, low cost and the ability to undergo large deformations. The obstacle of high driving voltages, however, limits the commercial viability of the technology at present. Higher strains at lower voltages can be obtained by creating elastomer materials with decreased thickness or Young's modulus, or alternatively increased dielectric permittivity according to the equation for actuation strain introduced by Pelrine et al. valid for small strains only [1,2].

$$
S=\frac{P_{e l}}{Y}=\frac{\varepsilon_{r} \varepsilon_{0}}{Y} E^{2}
$$

where $P_{e l}$, electrostatic pressure, is correlated to strain, $s$, and the elastic modulus, $Y$, and where $\varepsilon_{0}=8.854 \times 10^{-12} \mathrm{~F} / \mathrm{m}$ is vacuum permittivity, $E$ is the electric field and $\varepsilon_{r}$ is the relative dielectric permittivity of the elastomer film. Thus, reducing thickness has the greatest effect on decreasing driving voltage. Thicknesses as low as $20 \mu \mathrm{m}$ have been reported in current large-scale processing; further reductions could result in the increased importance of inhomogeneities and defects as well as other production-related difficulties [3]. However, other large-scale production processes inspired by, for example, spin coating could be developed in the future [3]. A great deal of focus during recent years has therefore been on increasing the dielectric permittivity of silicone DEs [4-10], which in turn leads to increased elastomer energy density and thereby increased strain at a given electric field. Large increases in dielectric permittivity have most often been accomplished through the use of metal oxide fillers creating silicone elastomer composites [11-15]. Such composite-type systems, though, do include the disadvantage that the Young's modulus of the elastomer is significantly increased - very 
often to a greater extent than dielectric permittivity - and thus no overall improvement in actuation strain is actually obtained.

Attempts at decreasing the driving voltage have also been made by decreasing the Young's modulus. These efforts include solvent techniques [16] and heterogeneous bimodal networks [17,18]. Furthermore, several research studies have attempted to create improved DEs through a combination of decreasing the Young's modulus and increasing dielectric permittivity, in order to achieve a synergistic impact that lowers driving voltage. These studies include the use of blends such as PDMS/poly(hexylthiophene) [19] and PDMS/polyethylene glycol [20,21] and a blend of a synthesised cyanopropyl-functional PDMS and a PDMS matrix, where the cyano-functional PDMS functions both as a high dielectric permittivity filler and as a silicone oil that softens the elastomer [22]. All of these materials showed improved electromechanical strain responses, since increased dielectric permittivities and decreased Young's moduli were obtained. The abovementioned elastomers, however, all had lower dielectric breakdown strength, due to increased dielectric losses. Dielectric losses are crucial for most DEs, since the heat generated due to dielectric losses results in substantial increases in both conductivity and temperature, and thus a destructive loop may occur which potentially leads to premature electrical [23-25] or thermal breakdown [26].

Very recently, we developed a promising silicone elastomer system based on chloropropyl-functional siloxane copolymers $[27,28]$. These chloropropyl-functional silicone elastomers possessed a low Young's modulus $(0.4$ $-1 \mathrm{MPa})$ and high dielectric permittivity $\left(\varepsilon^{\prime}=4.7\right.$ at $\left.1 \mathrm{MHz}\right)$. Dielectric losses, remarkably, remained as low as those associated with pure silicone elastomers. Nonetheless, although the recently developed technique via this specific synthesis procedure is facile and straightforward, polymer synthesis is inherently time-consuming.

The aim of this study is therefore to create a simple method for silicone elastomers with improved electromechanical strain response, using only commercially available components while exploiting the unique properties of chloropropyl-functional siloxanes. The new silicone elastomer matrix is therefore based on the addition of chloropropyl-functional silicone oil (LMS-152) to a commercial silicone elastomer (ELASTOSIL ${ }^{\circledR}$ LR3043/50), which is a simple mixing process. Increased dielectric permittivity stems from the high dipole moment of the chloropropyl groups. Silicone oil acts as a plasticiser in the tough and stiff LR3043/50 elastomer, and moreover the bulky nature of the chloropropyl groups yields a larger free volume around these groups than around the methyl groups on polydimethylsiloxane (PDMS), which results further in a less dense material with a lower Young's modulus. We will demonstrate how the final properties of DEs, such as dielectric losses, mechanical properties and dielectric breakdown strength, are influenced by the addition of chloropropyl-functional silicone oil to commercial silicone elastomer, and we will also show how we have solved, by a very simple approach, the frequently encountered issue of increased dielectric loss when increasing the dielectric permittivity of DEs.

\section{Experimental}

\subsection{Materials and methods}

Chloropropyl-functional silicone oil, LMS-152 $\left(\bar{M}_{w} \approx 9,000 \mathrm{~g} \mathrm{~mol}^{-1}\right)$, was acquired from Gelest Inc., while ELASTOSIL @ LR3043/50, inhibitor Pt88, solvent Belsil and Belsil resin (TMS 803) were acquired from Wacker Chemie AG. Rutile $\mathrm{TiO}_{2} \mathrm{R} 420$ and $\mathrm{TiO}_{2}$ Hombitec RM130F were purchased from Sachtleben. Differential scanning calorimetry (DSC) measurements were performed on a Discovery DSC from TA Instruments. The thermal analyses were performed with a heating and cooling rate of $10{ }^{\circ} \mathrm{C} \mathrm{min}{ }^{-1}$ from -180 $200{ }^{\circ} \mathrm{C}$. Linear viscoelastic (LVE) data, i.e. storage and loss moduli, were measured using an ARES-G2 rheometer (TA Instruments), set to a controlled strain mode of $1 \%$ strain and with frequency sweeps ranging from $100 \mathrm{~Hz}$ to $0.01 \mathrm{~Hz}$ at room temperature (RT) in an ambient atmosphere, and a parallel-plate geometry 25 
$\mathrm{mm}$ in diameter. The morphology of samples with $30 \mathrm{phr}$ and $100 \mathrm{phr}$ LMS-152 was investigated with a Leica optical microscope at RT, using cross-sectional film cuts. The morphology of samples was examined by scanning electron microscopy (SEM) (FEI Inspect S, USA). The samples were firstly immersed into liquid nitrogen for a few minutes, then broken and deposited on a sample holder. All samples were coated with gold under vacuum before test. Energy dispersive X-ray (EDX) spectroscopy (Oxford INCAWave 500, UK) was applied to detect the element distribution profile on the surface of the samples. The films' stress-strain curves were measured at RT using the ARES-G2 rheometer with a SER2 universal testing platform. The $20 \mathrm{~mm}$ in length and $6 \mathrm{~mm}$ in width sample was placed between two drums separated by a distance of $12.7 \mathrm{~mm}$. The test specimen was elongated uniaxially at a steady Hencky strain rate of $0.01(1 / \mathrm{s})$ until sample failure in the middle part of the sample. The Young's moduli of the films were determined from the tangent of the stress-strain curves for a strain of 5\%. Each sample composition was subjected to four tensile measurements which were then averaged. Typical standard deviations in tensile measurements were of the order $+/-5 \%$. Dielectric relaxation spectroscopy (DRS) was performed on a Novocontrol Alpha-A high-performance frequency analyser (Novocontrol Technologies $\mathrm{GmbH} \& \mathrm{Co}$ ) operating in the frequency range $10^{-1}-10^{6} \mathrm{~Hz}$ at room temperature and low electrical field $(\sim 1 \mathrm{~V} / \mathrm{mm})$. The diameter of the tested $0.5-1 \mathrm{~mm}$ thick samples was $25 \mathrm{~mm}$. Electrical breakdown tests were performed on an in-house-built device based on international standards (IEC 60243-1 (1998) and IEC 60243-2 (2001)), while film thicknesses ( 80 $\mu \mathrm{m})$ were measured through the microscopy of cross-sectional cuts. The distance between the spherical electrodes was set accordingly with a micrometre stage and gauge. An indent of less than 5\% of sample thickness was added, to ensure that the spheres were in contact with the sample. The non-stretched elastomer film was slid between the two spherical electrodes (radius of $20 \mathrm{~mm}$ ), and the breakdown was measured at the point of contact by applying a stepwise increasing voltage (50-100 V/step) at a rate of 0.5-1 steps/s. Each sample was subjected to 12 breakdown measurements, and an average of these values was given as the breakdown strength of the sample. Post-curing was performed by heating the cured samples additionally at $200^{\circ} \mathrm{C}$ for 4 hours as suggested in Brook et al.[29]. The mechanical and dielectric properties of the samples were hereafter tested again. Circular strain tests were carried out to measure actuation strain. The dielectric elastomer film was fixed on a circular frame with $75 \%$ pre-strain (diameter based). Circular electrodes (diameter of $20 \mathrm{~mm}$ ) consisting of carbon grease were sprayed on. The area strain was defined as the change in the area of electrodes divided by the original area $\left(314 \mathrm{~mm}^{2}\right)$. The voltage was supplied by a high-voltage alternating current generator with maximum of $5 \mathrm{kV}$. In order to measure changes in electrode area, a video camera was fixed above the elastomer film to capture the actuator plane before and after applying the voltage. The area strain (actuation strain) is calculated according to: $\mathrm{S}_{\mathrm{A}}=\left(\mathrm{A}-\mathrm{A}_{0}\right) / \mathrm{A}_{0} \times 100 \%$, where $\mathrm{A}$ is the area of the electrodes in the actuated state, and $\mathrm{A}_{0}$ is the original area of the electrodes $\left(314 \mathrm{~mm}^{2}\right)$.

\subsection{General procedure for elastomer synthesis with chloropropyl-functional silicone oil}

An appropriate amount of LMS-152 was mixed with commercial two-component silicone mixture, ELASTOSIL ${ }^{\circ}$ LR3043/50 (mixed in a 1:1 ratio) (one component was added first), filler materials $\left(\mathrm{TiO}_{2}\right)$, resin (Belsil) and solvent (Belsil, 30-50 phr), as indicated in Table 1, using a Speedmixer. The second elastomer component and inhibitor were then added, and the mixture was speed-mixed once more. The mixture was then poured into a $1 \mathrm{~mm}$ thick steel mould, coated as thin films, using a $150 \mu \mathrm{m}$ thick doctor blade, on a glass substrate and then cured at $115^{\circ} \mathrm{C}$ for 1 hour. The different sample compositions and quantities can be found in Table 1. 
Table 1. Compositions and quantities of the samples prepared with chloropropyl-functional silicone oil.

\begin{tabular}{|c|c|c|c|c|c|c|}
\hline \multirow[b]{2}{*}{ Entry } & \multirow[b]{2}{*}{ Composition } & \multicolumn{5}{|c|}{ Quantities } \\
\hline & & $\begin{array}{l}\text { LMS- } \\
152\end{array}$ & LR3043/50A & LR3043/50B & $\mathrm{TiO}_{2}$ & $\begin{array}{l}\text { Belsil } \\
\text { resin }\end{array}$ \\
\hline LR3043/50 & Reference sample with LR3043/50 & - & $5.00 \mathrm{~g}$ & $5.00 \mathrm{~g}$ & - & - \\
\hline $10 \mathrm{phr}$ & LR3043/50+ 10phr* LMS-152 & $1.00 \mathrm{~g}$ & $5.00 \mathrm{~g}$ & $5.00 \mathrm{~g}$ & - & - \\
\hline $20 \mathrm{phr}$ & LR3043/50+ 20phr ${ }^{*}$ LMS-152 & $2.00 \mathrm{~g}$ & $5.00 \mathrm{~g}$ & $5.00 \mathrm{~g}$ & - & - \\
\hline $30 \mathrm{phr}$ & LR3043/50+ 30 phr $^{*}$ LMS-152 & $3.00 \mathrm{~g}$ & $5.00 \mathrm{~g}$ & $5.00 \mathrm{~g}$ & - & - \\
\hline $40 \mathrm{phr}$ & LR3043/50+ 40 phr $^{*}$ LMS-152 & $4.00 \mathrm{~g}$ & $5.00 \mathrm{~g}$ & $5.00 \mathrm{~g}$ & - & - \\
\hline $70 \mathrm{phr}$ & LR3043/50+ 70 phr $^{*}$ LMS-152 & $7.00 \mathrm{~g}$ & $5.00 \mathrm{~g}$ & $5.00 \mathrm{~g}$ & - & - \\
\hline $100 \mathrm{phr}$ & LR3043/50+ 100 phr $^{*}$ LMS-152 & $10.0 \mathrm{~g}$ & $5.00 \mathrm{~g}$ & $5.00 \mathrm{~g}$ & - & - \\
\hline 100 phr+Belsil & $\begin{array}{l}\text { LR3043/50+ } 100 \text { phr }^{*} \text { LMS- } \\
152+5 \mathrm{wt} \% \text { Belsil resin }\end{array}$ & $10.0 \mathrm{~g}$ & $5.00 \mathrm{~g}$ & $5.00 \mathrm{~g}$ & - & $1.00 \mathrm{~g}$ \\
\hline $30 \mathrm{phr} \mathrm{TiO}_{2}(1)$ & LR3043/50+ 30phr* $\mathrm{TiO}_{2}(\mathrm{R} 420)$ & - & $2.50 \mathrm{~g}$ & $2.50 \mathrm{~g}$ & $1.50 \mathrm{~g}$ & - \\
\hline $\begin{array}{l}30 \mathrm{phr}+30 \mathrm{phr} \\
\mathrm{TiO}_{2}(1)\end{array}$ & $\begin{array}{l}\text { LR3043/50+ } 30 \text { phr* LMS- }^{*} \text { 152+5wt\% Belsil resin+30phr* } \mathrm{TiO}_{2} \\
\text { (R 420) }\end{array}$ & $1.50 \mathrm{~g}$ & $2.50 \mathrm{~g}$ & $2.50 \mathrm{~g}$ & $1.50 \mathrm{~g}$ & $0.40 \mathrm{~g}$ \\
\hline $30 \mathrm{phr} \mathrm{TiO}_{2}(2)$ & LR3043/50+30 phr $^{*} \mathrm{TiO}_{2}($ Hombitec $)$ & - & 3.00 & $3.00 \mathrm{~g}$ & $1.80 \mathrm{~g}$ & - \\
\hline $\begin{array}{l}30 \mathrm{phr}+30 \mathrm{phr} \\
\mathrm{TiO}_{2}(2)\end{array}$ & $\begin{array}{l}\text { LR3043/50+ } 30 \text { phr}^{*} \text { LMS- } \\
\text { 152+5wt } \% \text { Belsil resin+30phr* } \mathrm{TiO}_{2} \\
\text { (Hombitec) }\end{array}$ & $1.80 \mathrm{~g}$ & 3.00 & $3.00 \mathrm{~g}$ & $1.80 \mathrm{~g}$ & $0.48 \mathrm{~g}$ \\
\hline
\end{tabular}

\section{Results and discussion}

Silicone elastomers with high dielectric permittivity and low Young's moduli were prepared by a simple mixing process using chloropropyl-functional siloxane polymers. The approach was based on the addition of chloropropyl-functional silicone oil, LMS-152, Figure 1, to a tough commercial silicone elastomer with excellent mechanical properties.

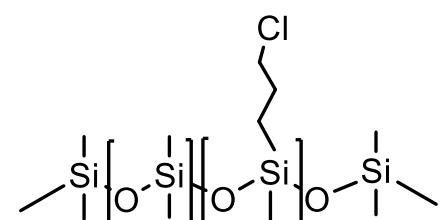

Figure 1. Structure of LMS-152 chloropropyl-functional silicone oil.

Chloropropyl-functional silicone oil was mixed into the commercially available ELASTOSIL® LR3043/50 elastomer system, a two-part (A and B) liquid silicone rubber (LSR) mixed in a 1:1 ratio. More details on the characteristics of LSRs can be found in the work by Delebecq et al.[30,31]. A sample containing a high concentration of LMS-152 (100 phr) was furthermore reinforced with $5 \mathrm{wt} \%$ Belsil resin (TMS 803). A reference sample consisting of pure ELASTOSIL® LR3043/50 was also prepared. All sample compositions can be seen in Table 1.

The viscoelastic properties of the samples prepared with chloropropyl-functional silicone oil were measured by linear shear rheology, and the resulting shear storage moduli (G') and viscous losses ( $\tan \delta_{\text {visc }}$ ) are shown in Figure 2 and summarised in Table 3. The elastomers became increasingly softer in line with an increasing amount of LMS-152 silicone oil, as expected. Moreover, losses, represented as $\tan \delta_{\text {visc, }}$ also increased in line with an increasing amount of silicone oil, which was again expected, due to the larger amounts of non-bonded structures in the networks which give rise to viscoelastic relaxation. These viscoelastic losses, however, remained very low with the addition of up to $30 \mathrm{phr}$ LMS-152. Above $40 \mathrm{phr}$, significant relaxation could be 
observed ( $\tan \delta_{\text {visc }}$ became concave). Moreover, it was evident that the addition of $5 \mathrm{wt} \%$ Belsil resin to the very soft $100 \mathrm{phr}$ sample reinforced the network such that viscoelastic losses improved two-fold, thereby indicating that resin partly immobilises the silicone oil and leads to an overall improved network.
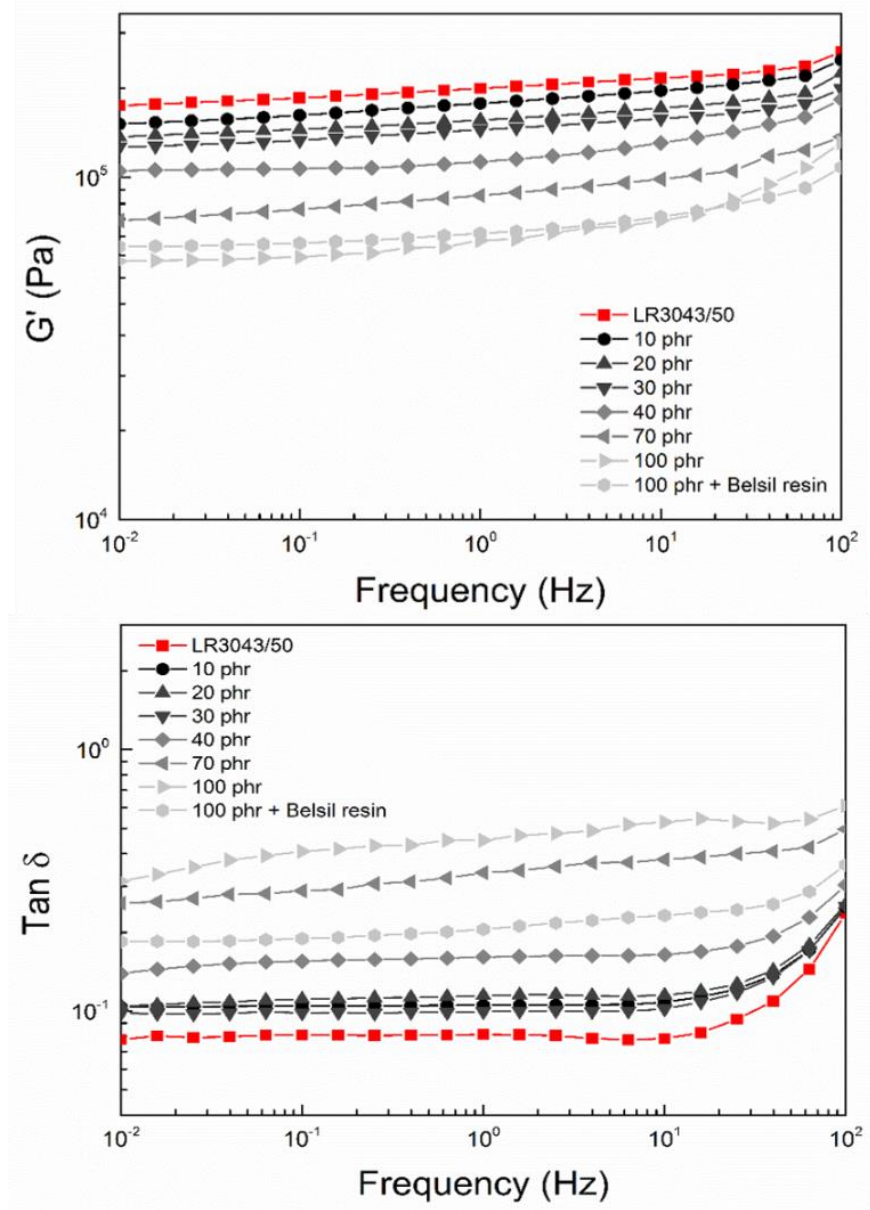

Figure 2. Storage moduli (G') and viscous $\operatorname{loss}\left(\tan \delta_{\text {visc }}\right)$ as functions of frequency for elastomers prepared with chloropropyl-functional silicone oil.

Tensile tests were performed on the elastomers with LMS-152, for which the resulting stress-strain curves are presented in Figure 3. The Young's moduli at 5\% strain and the maximum stress and strain are shown in Table 3. The stress-strain curves corroborate the increasing soft nature of the elastomer samples with LMS152 silicone oil, since stress at break and the Young's moduli decrease in line with increasing content. Up to 30 phr LMS-152 the strain at break increases in line with increasing LMS-152 loading, whereas thereafter strain at break significantly decreases as content increases. This is due to concentration of LMS- 152 becoming so high, that the network becomes weaker, i.e. the elastic properties of the network are destroyed. The addition of Belsil resin improves stress and strain at break somewhat for a $100 \mathrm{phr}$ sample. All films show weak strainsoftening behaviour. 


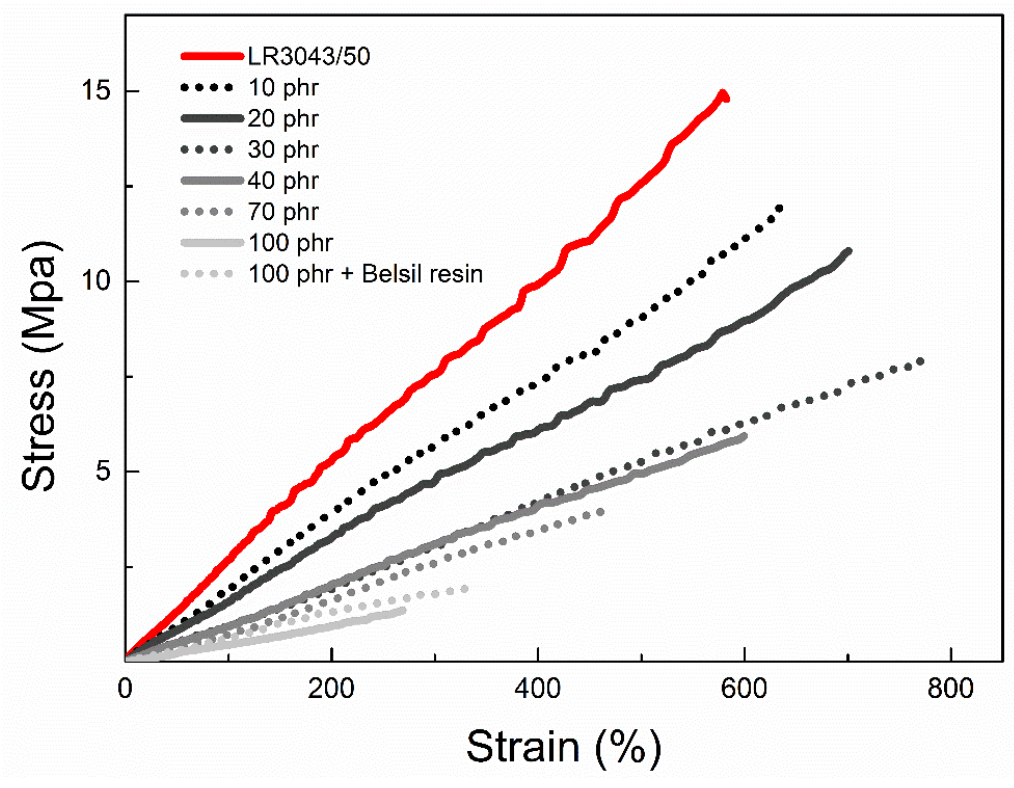

Figure 3. Stress-strain curves for elastomers prepared with chloropropyl-functional LMS-152.

The destruction of the networks at high LMS-152 loading is corroborated by microscopy images (Figure 4) obtained from the cross-sectional cuts of samples with $30 \mathrm{phr}$ and $100 \mathrm{phr}$ LMS-152 where it is clear that whereas the sample containing $30 \mathrm{phr}$ silicone oil was a completely homogenous film, the sample containing $100 \mathrm{phr}$ silicone oil experienced severe internal phase separation. This was further substantiated by SEM images of surfaces and cross-sectional cuts of the 30 and $100 \mathrm{phr}$ samples as well as pure LR3043/50 as shown in Figure 5. It can be seen that the $100 \mathrm{phr}$ sample had extensive phase separation compared to pure LR3043/50 and the $30 \mathrm{phr}$ sample. The $30 \mathrm{phr}$ sample showed slightly increased surface roughness, but negligible compared to the $100 \mathrm{phr}$ sample.

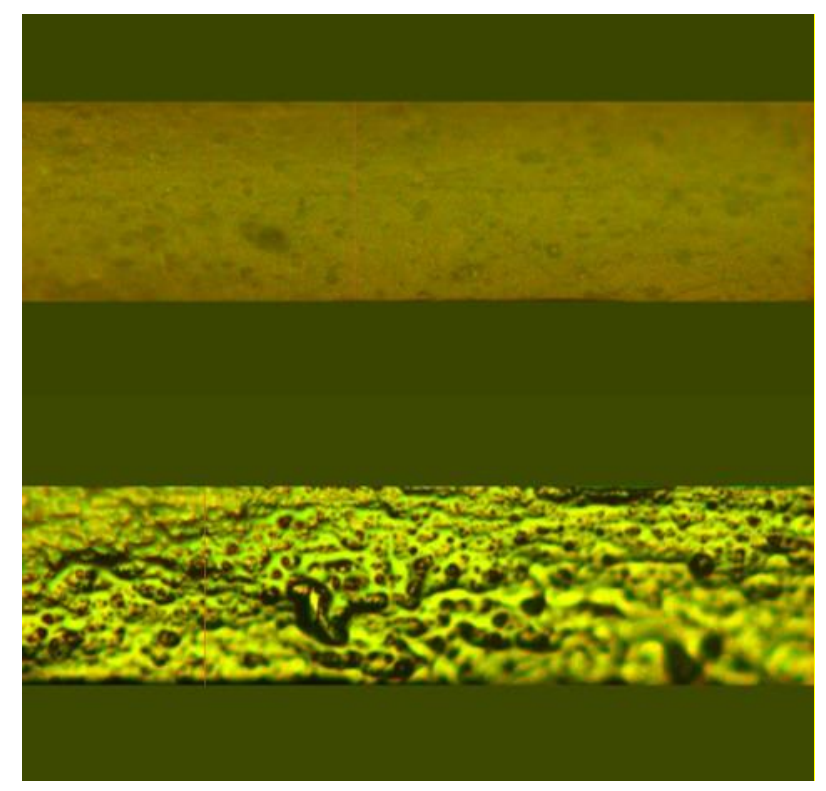

Figure 4. Microscopy images of cross-sectional cuts of samples with $30 \mathrm{phr}$ (top) and $100 \mathrm{phr}$ (bottom) LMS-152. The samples are $62.6 \mu \mathrm{m}$ and $60.0 \mu \mathrm{m}$ thick, respectively. 


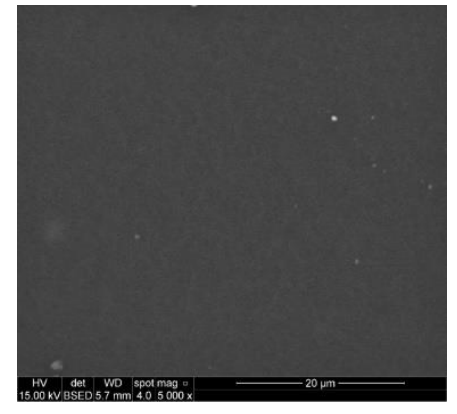

LR3043/50 surface

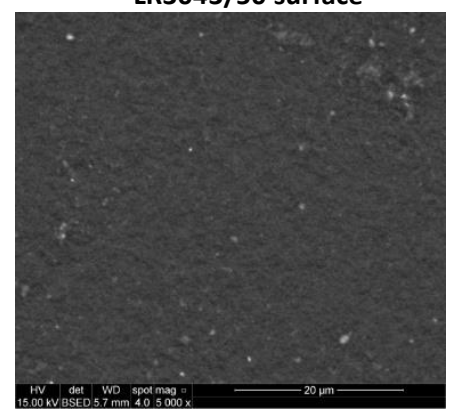

$30 \mathrm{phr}$ surface

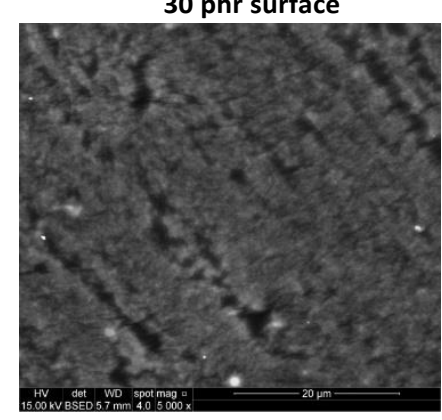

$100 \mathrm{phr}$ surface

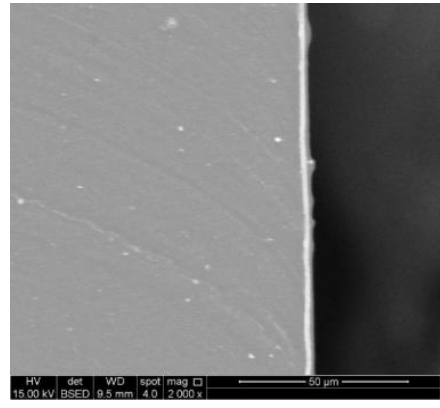

LR3043/50 cross-section

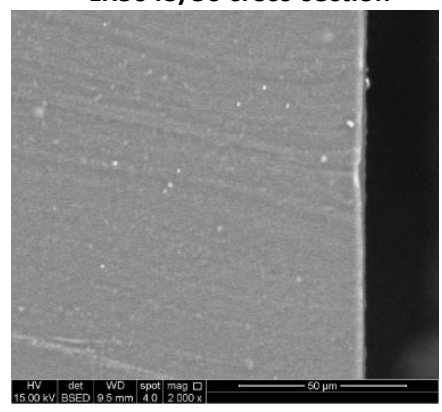

30 phr cross-section

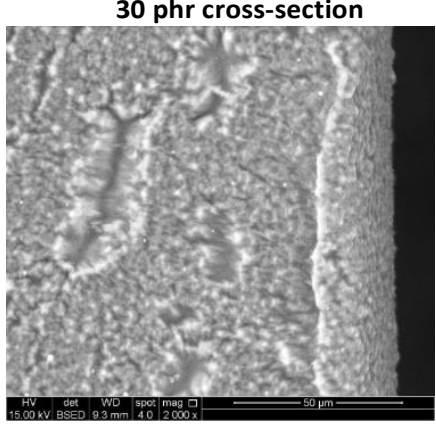

100 phr cross-section

Figure 5. SEM images of surfaces and cross-sectional cuts of samples with 30 and 100 phr LMS-152 as well as pure LR3043/50.

The thermal transition behaviour of the samples was determined by differential scanning calorimetry (DSC) and the resulting thermograms can be found in supporting information. From these results it is clear that the melting and crystallisation temperatures were similar for pure LR3043/50 and the $30 \mathrm{phr}$ sample whereas the sample with $100 \mathrm{phr}$ LMS-152 showed reduced melting temperature and significantly reduced crystalline behaviour, which was deduced from the area under the crystallisation peak. These results agree with the microscopy results and further elucidate the significant plasticisation effect exhibited by $100 \mathrm{phr}$ LMS-152. On the other hand, there was no clear evidence of two glass transition temperatures, even at high concentration of LMS-152, which is usually a sign of phase separation on the microscale. This may be due to the high compatibility between the silicone matrix and the silicone based oil. Ageing (post-cure for 4 hours at $200^{\circ} \mathrm{C}$ ) did on the other hand not change the mechanical properties of the LMS-152 filled samples to a different extent than for pure LR3043/50. As expected all samples became stiffer by post-cure as the cross-link density increased and consequently the stress and strain at break were reduced. However, this reduction was within a similar range for all samples irrespective of LMS-152 concentration. The dielectric properties and the conductivity did not change with post-cure (more than what was within the experimental error). All ageing results can be found as supporting information. 
Dielectric permittivity as a function of frequency is shown in Figure 6 and depicted further as a function of LMS-152 loading in Figure 7. Dielectric permittivity increases as the content of chloropropyl-functional silicone oil increases, reaching $\varepsilon^{\prime}=5.5$ at $100 \mathrm{~Hz}$ for the elastomer with $100 \mathrm{phr}$ LMS-152. This corresponds to an increase of $104 \%$ compared to the pure LR3043/50 elastomer for which $\varepsilon^{\prime}=2.7$ at $100 \mathrm{~Hz}$.
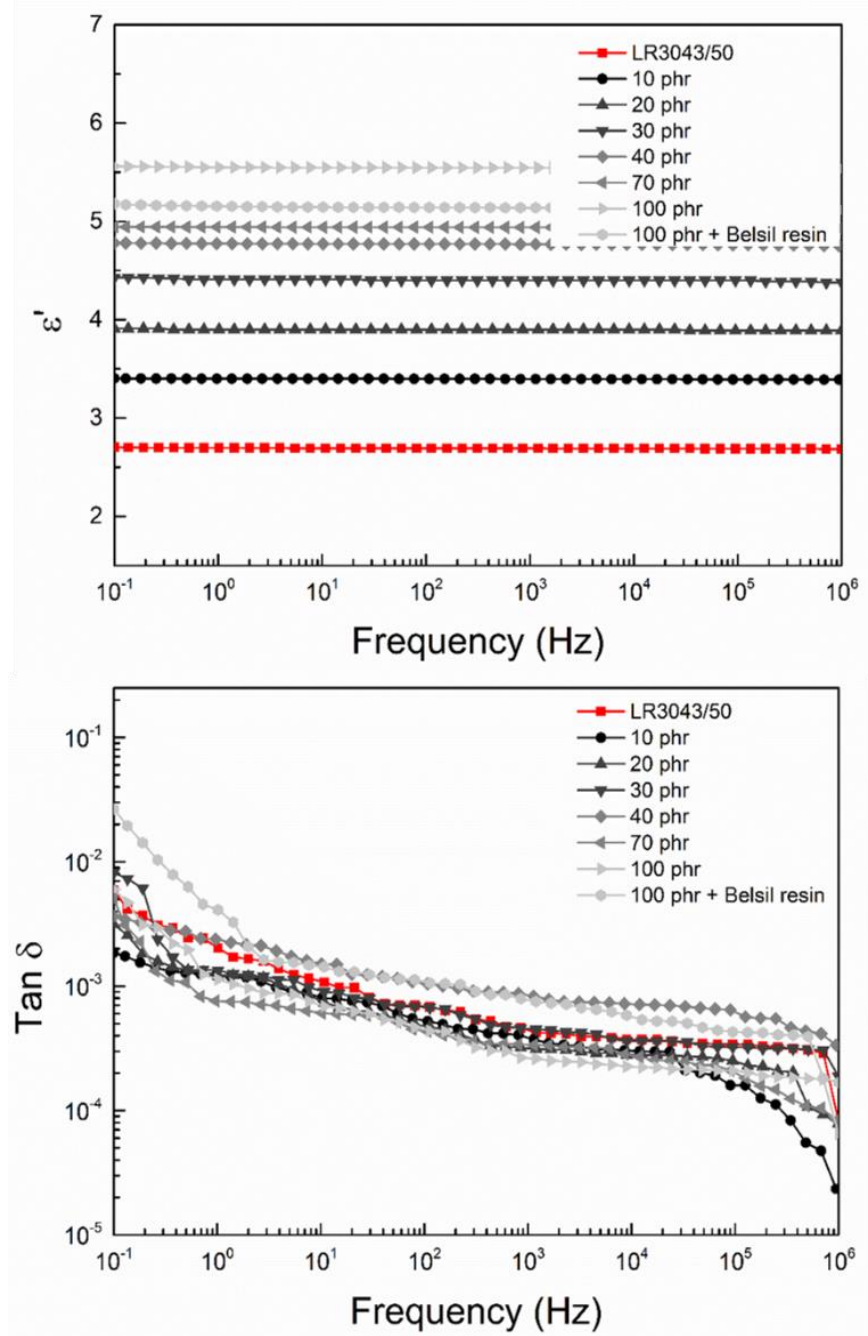

Figure 6. Dielectric permittivity $\left(\varepsilon^{\prime}\right)$ and loss tangent $(\tan \delta)$ as functions of frequency for elastomers prepared with chloropropyl-functional silicone oil LMS-152. 


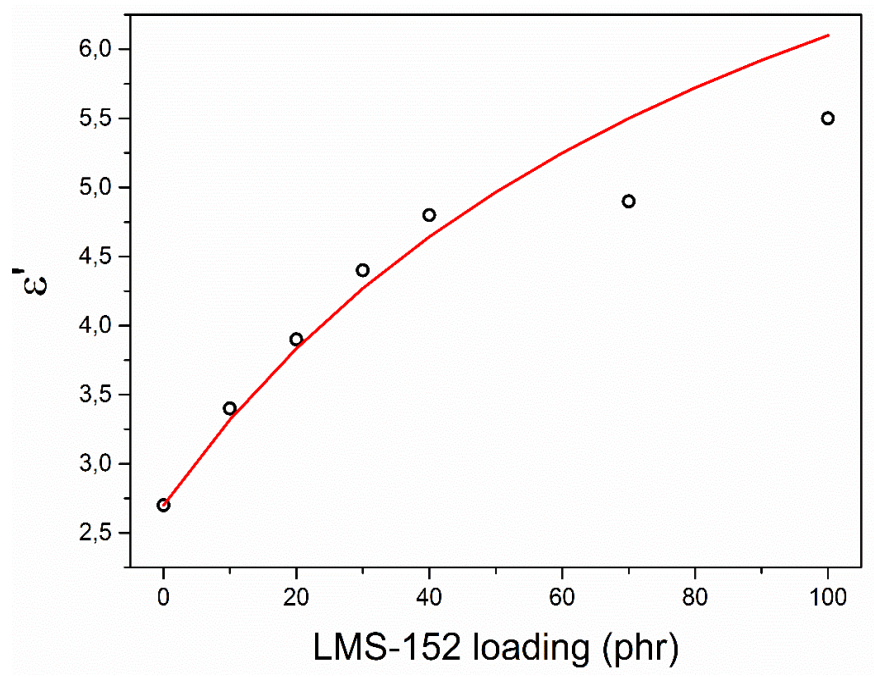

Figure 7. Dielectric permittivity as a function of LMS-152 loading. The solid line indicates a fit to a linear mixing rule, where the permittivity of high-permittivity part is artificially set to 9.5 and silicone permittivity set to 2.7 .

To interpret the results a comparison between the classical linear mixing rule [32] and the data was performed. The linear mixing rule can be expressed as:

$\varepsilon_{\mathrm{m}}=\mathrm{V}_{\mathrm{a}} \varepsilon_{\mathrm{a}}+\mathrm{V}_{\mathrm{b}} \varepsilon_{\mathrm{b}}$

where $\varepsilon_{\mathrm{m}}$ is the dielectric permittivity of the mixture and $\varepsilon_{\mathrm{a}}$ and $\varepsilon_{\mathrm{b}}$ are the dielectric permittivity of the high and low permittivity phases, respectively, and $\mathrm{V}_{\mathrm{a}}$ and $\mathrm{V}_{\mathrm{b}}$ are the volume fractions of the high and low permittivity phases, respectively. The linear mixing rule can be derived easily as a function of parts per hundred rubber:

$\varepsilon_{\mathrm{m}}=\varepsilon_{\mathrm{b}}+(\mathrm{phr} /(100+\mathrm{phr}))\left(\varepsilon_{\mathrm{a}}-\varepsilon_{\mathrm{b}}\right)$

It is clear from Figure 7 that the increase in dielectric permittivity as a function of LMS-152 loading does not follow the general linear dielectric constant mixing rule. The model only predicts the properties if the dielectric permittivity of the high-permittivity part (chloropropyl-functional silicone oil) is set artificially to $\varepsilon^{\prime}=9.5$ (value found by least-square fitting of linear mixing rule to experimental data), which gives a clear indication that the simple linear mixing rule does not capture ongoing phenomena in the resulting elastomers. Several other mixing rules have been proposed for predicting the relationship between dielectric permittivity and the volume fractions of materials with high dielectric permittivity fillers, including the Maxwell-Wagner equation [33,34] and the RotherLichtenecker model [35]. These models however, are only valid for composites with hard fillers, whereas the filler used in this study is a soft and flexible polymer. This may lead to the large variations in relation to the classical linear dielectric permittivity mixing rule which we have illustrated in Figure 7. In the supplementary information we have shown fittings by various models to the data, and it is clear that the traditional mixing laws do not hold for this type of composite. The data is, however, promising despite not fitting to the interpretation of any model.

By adding Belsil resin to the elastomer with $100 \mathrm{phr}$ silicone oil, dielectric permittivity drops slightly to $\varepsilon^{\prime}=5.1$ at $100 \mathrm{~Hz}$, due to the diluting effect of the resin, which does not contribute with significant dielectric permittivity. Interestingly, this increase in dielectric permittivity is not followed by an 
increase in dielectric losses $(\tan \delta$ ), as seen in Figure 6; in fact, most of the samples with LMS-152 have lower dielectric losses than the commercial elastomer LR3043/50. To our knowledge there are no reports of other elastomer systems with such properties, since increases in dielectric permittivity are generally followed by large increases in dielectric losses. Consequently, the addition of LMS-152 to silicone elastomers constitutes a simple and easy method of decreasing or maintaining suitable levels of dielectric losses in silicone DEs.

Low conductivity is also a key element in dielectric elastomer performance, and it is important to make sure that the composites do not possess conductivity. Conductivity as a function of frequency for elastomers prepared with chloropropyl-functional silicone oil is shown in Figure 8. It can be seen in Figure 8 that conductivity remains very low for all samples prepared with chloropropyl-functional silicone oil. Only the sample prepared with Belsil resin experiences increased conductivity at low frequencies, but this remains at a negligible level.

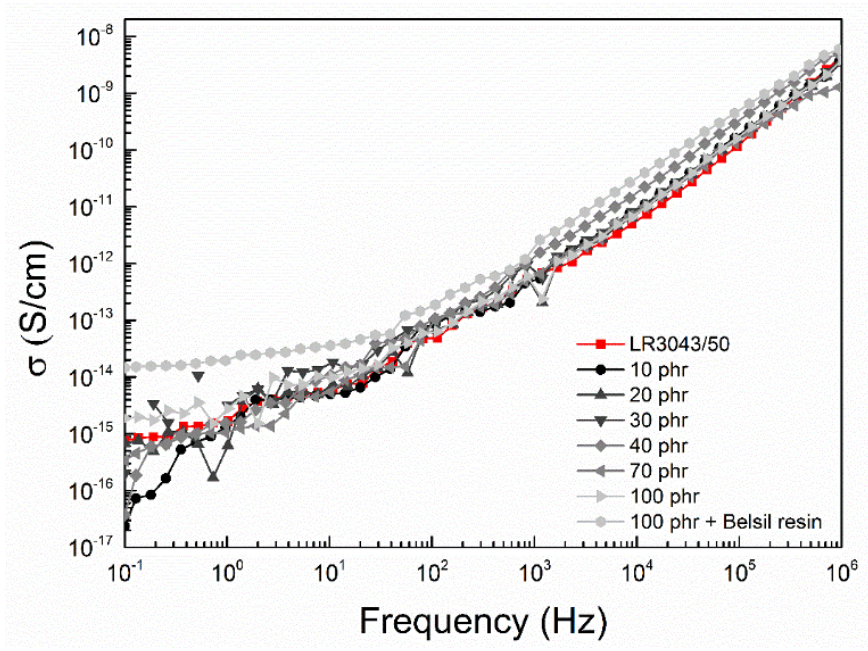

Figure 8. Conductivity as a function of frequency for elastomers prepared with chloropropyl-functional silicone oil.

The results of the dielectric breakdown strength measurements are shown in Table 3. The addition of low amounts of chloropropyl silicone oil to the commercial silicone elastomers is seen to increase breakdown strength, even though the materials become softer. Thereafter, breakdown strength decreases as the content of LMS-152 increases, probably due to the significantly decreased stiffness/moduli of the elastomers at this concentration of silicone oil, since stiffness has a major impact on breakdown strength - as shown in previous studies, where it was found that breakdown strength was proportional to the Young's modulus [36,37]. This means that up to $30 \mathrm{phr}$ LMS-152 can be added to commercial formulations without compromising dielectric, mechanical and, ultimately, DE properties.

In order to gain a more detailed understanding of the breakdown strengths, Weibull analyses were performed. Weibull analysis can provide further insights into electrical reliability. The data are fitted to the Weibull cumulative distribution:

$F\left(E_{B}\right)=1-\exp \left(-\frac{E_{B}}{\eta}\right)^{\beta}$

where $\eta$ is the so-called scale parameter which is determined from the distribution at which $63.2 \%$ of the films have broken down electrically. $\beta$ is the shape parameter indicating the width of the distribution. In order to fit 
the experimentally determined breakdown data points $\left(E_{\mathrm{B}}\right)$ to the Weibull distribution, the expression in Equation 4 is linearized to give:

$\ln \left[\ln \left(\frac{1}{1-F\left(E_{B}\right)}\right)\right]=\beta \cdot \ln \left(E_{B}\right)-\beta \cdot \ln (\eta)$

The Median Ranks method is used to obtain an estimate of the unreliability for each failure, i.e.

$F\left(E_{B}\right) \sim M R(i) \sim \frac{i-0.3}{N+0.4} \cdot 100$

where the median rank is the value that the true probability of failure, $F\left(E_{\mathrm{B}}\right)$, should have at the jth failure out of a sample of $N$ units at the $50 \%$ confidence level. Thereby the left side of Equation 5 as function of $\ln \left(E_{\mathrm{B}}\right)$ and thereby $\beta$ can be found as the slope of the linear regression and the product $(\beta \cdot \ln (\eta))$ as the intersection. Both parameters are of great importance to DEs. $\eta$ should be as high as possible, in close agreement with traditional measurements of electrical breakdown strengths. However, for reliability, $\beta$ is also required to be as large as possible, i.e. the measured breakdown strengths all fall within a narrow range of voltages. This is also a clear indication of homogeneity on the microscale. The determined parameters are shown in Table 2 and plotted in Figure 9.

Table 2. Weibull parameters for the samples with chloropropyl-functional silicone oil as well as the correlation fit between data and model.

\begin{tabular}{ccccc}
\hline $\begin{array}{c}\text { Film with } \\
\text { entry }\end{array}$ & $\begin{array}{c}\text { Number of } \\
\text { measurements }\end{array}$ & $\begin{array}{c}\text { Scale } \\
\text { parameter } \eta \\
{[\mathrm{V} / \mu \mathrm{m}]}\end{array}$ & $\begin{array}{c}\text { Shape } \\
\text { parameter } \beta\end{array}$ & $\mathrm{r}^{2}$ \\
\hline LR3043/50 & 10 & 123 & 33 & 0.95 \\
$10 \mathrm{phr}$ & 10 & 144 & 29 & 0.96 \\
$20 \mathrm{phr}$ & 10 & 153 & 44 & 0.98 \\
$30 \mathrm{phr}$ & 10 & 132 & 27 & 0.99 \\
$40 \mathrm{phr}$ & 10 & 120 & 35 & 0.95 \\
$70 \mathrm{phr}$ & 10 & 101 & 31 & 0.96 \\
$100 \mathrm{phr}$ & 10 & 84 & 33 & 0.70 \\
\hline
\end{tabular}

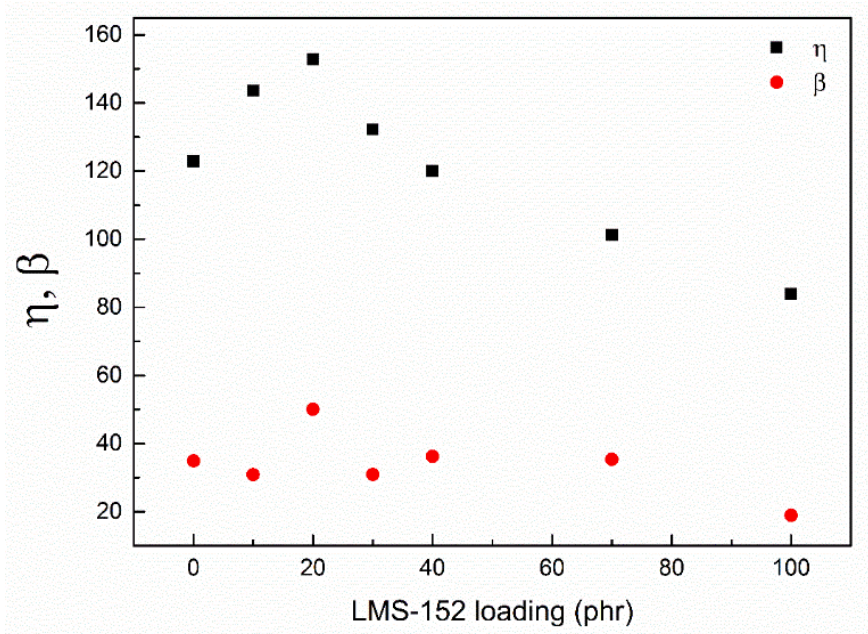

Figure 9. Weibull data for samples with chloropropyl-functional silicone oil. The scale parameter $\eta$ is given in units of $\mathrm{V} / \mu \mathrm{m}$.

From Figure 9 it is clear that the most favourable composition with respect to electrical breakdown and reliability is found around 10-30 phr of chloropropyl-functional silicone oil (where $20 \mathrm{phr}$ corresponds to a 
volume fraction of oil of $\varphi=0.16$ ). These compositions possess both the highest $\beta$ and $\eta$, which indicates very homogeneous films with good electrical properties. This agrees well with the fact that these samples have decreased viscosities compared to pure LR3043/50 which affords easier film-coating. At the same time these films do not have significantly reduced Young's moduli compared to films with higher concentration of chloropropyl-functional silicone oil and they therefore maintain their resistance to compression upon application of a Maxwell pressure. At higher loadings the films become very soft, due to the presence of significant amounts of oil. For the $100 \mathrm{phr}$ sample the observed Weibull distribution agrees well with the microscopy results, namely that the sample is very inhomogeneous, with almost a two-fold decrease in $\eta$ compared to the samples with 30-70 phr LMS-152.

The figure of merit, $F_{o m}$, is a universal expression, defined by Sommer-Larsen and Larsen[38], which through a single parameter can be used to evaluate the performance of a DE at the maximal applicable potential. The figure of merit depends on the dielectric constant, dielectric breakdown strength and the Young's modulus ( $Y$ $\left.=3 \mathrm{G}^{\prime}\right)$ of the elastomer and is defined as:

$F_{o m}=\frac{3 \varepsilon \cdot E_{B}{ }^{2}}{Y}=\frac{\varepsilon^{\prime} \cdot E_{B}{ }^{2}}{G \prime}$

The overall DE properties of the elastomers with the chloropropyl-functional silicone oil can be compared to the properties of the commercial elastomer by calculating the $F_{\text {om }}$ of a given sample relative to the $F_{\text {om }}$ of the reference material $\left(F_{\text {om }} / F_{\text {om }}\right.$ ref $)$, for which the results are shown in Figure 10 and Table 3 (calculated using $Y$ ). The figure of merit calculations indicate the combined effect of the chloropropyl-functional silicone oil on the properties of the commercial elastomer ELASTOSIL ${ }^{\circledR}$ LR3043/50. It is evident that all of the samples with chloropropyl-functional silicone oil improved their overall properties compared to the pure silicone elastomer, for which the samples with $30 \mathrm{phr}$ and $100 \mathrm{phr}$ show the highest improvement in DE properties.

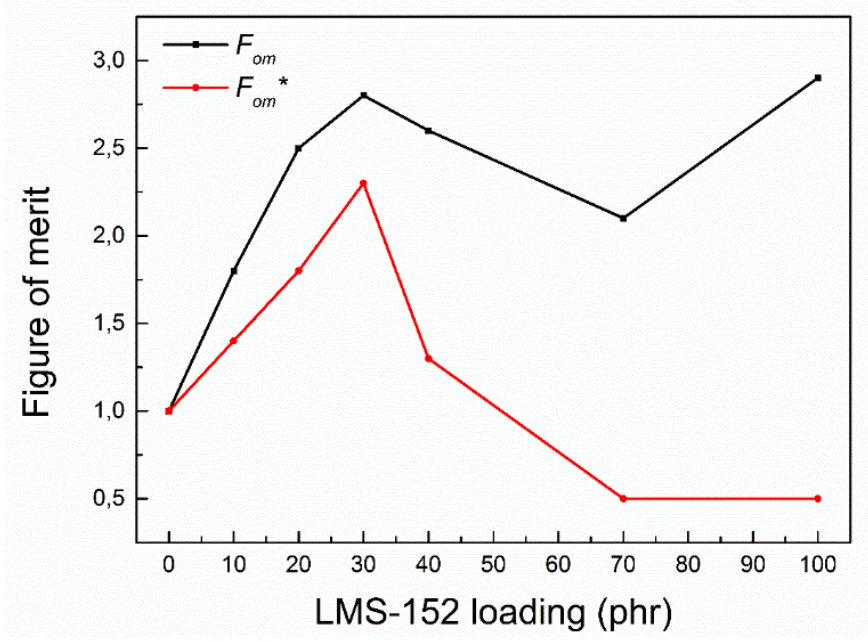

Figure 10. Figure of merit as a function of LMS-152 loading.

Recently, a newly adjusted figure of merit expression was introduced that takes losses into account[39]. As a result, the figure of merit is coupled to the heat conduction of the DE element which arises from either dielectric or viscous losses. In this study, due to the use of silicone oil, viscous losses are more significant than dielectric losses, which vary marginally between the different samples, and therefore only viscous losses are introduced into the adjusted figure of merit equation:

$F_{\text {om }}^{*}=F_{\text {om }} \cdot \frac{1}{\tan \delta_{\text {visc }}}$ 
The results of the adjusted figure of merit calculations are shown in Table 3 and Figure 10. From the calculations it is clear that when losses are taken into account, low concentrations of LMS-152 silicone oil produce elastomers with the best DE qualities and the greatest predicted improvements in actuation strain. The best improvement in predicted actuation strain is obtained for the sample prepared with $30 \mathrm{phr}$ LMS-152, where an over two-fold predicted increase is observed.

Table 3. Summary of dielectric permittivity $\left(\varepsilon^{\prime}\right)$ and loss tangent $(\tan \delta)$ at $100 \mathrm{~Hz}$, breakdown strengths $\left(E_{\mathrm{B}}\right)$, storage moduli $\left(\mathrm{G}^{\prime}\right)$ and loss $\left(\tan \delta_{\text {visc }}\right)$, Young's moduli, tensile tests as well as the figure of merit for elastomers with chloropropyl-functional silicone oil, LMS-152, as an additive to ELASTOSIL® LR3043/50.

\begin{tabular}{|c|c|c|c|c|c|c|c|c|c|c|c|}
\hline \multirow[b]{2}{*}{$\begin{array}{l}\text { Film with } \\
\text { entry }\end{array}$} & \multicolumn{2}{|c|}{ Dielectric spectroscopy } & \multirow{2}{*}{$\begin{array}{c}\text { Conductivit } \\
\qquad \begin{array}{c}\mathrm{y} \\
\sigma @ 1 \mathrm{~Hz} \\
{[\mathrm{~s} / \mathrm{cm}]}\end{array}\end{array}$} & \multirow{2}{*}{$\begin{array}{c}\text { Electrical } \\
\text { breakdown } \\
E_{\mathrm{B}} \\
{[\mathrm{V} / \mu \mathrm{m}]}\end{array}$} & \multicolumn{2}{|c|}{ Rheology } & \multicolumn{3}{|c|}{ Tensile tests } & \multirow{2}{*}{$\begin{array}{c}\text { Figure } \\
\text { of merit } \\
F_{\text {om }} / \\
F_{\text {om_ref }}\end{array}$} & \multirow{2}{*}{$\begin{array}{c}\text { Adjusted } \\
\text { figure of } \\
\text { merit } \\
F_{\text {om* }} / \\
F_{\text {om_ref* }}\end{array}$} \\
\hline & $\begin{array}{c}\varepsilon^{\prime} \\
@ 100 \mathrm{~Hz}\end{array}$ & $\begin{array}{c}\tan \delta \\
@ 100 \mathrm{~Hz}\end{array}$ & & & $\begin{array}{c}\mathrm{G}^{\prime} \\
@ 1 \mathrm{~Hz} \\
{[\mathrm{kPa}]}\end{array}$ & $\begin{array}{c}\tan \\
\delta_{\text {visc }} \\
@ 1 \mathrm{~Hz}\end{array}$ & $\begin{array}{c}\text { Y@ } \\
5 \% \\
\text { strain } \\
{[\mathrm{MPa}]} \\
\end{array}$ & $\begin{array}{l}\text { Max. } \\
\text { stress } \\
\mathrm{MPa}\end{array}$ & $\begin{array}{c}\text { Strain at } \\
\text { break } \\
\% \\
\%\end{array}$ & & \\
\hline LMS-152 & 5.1 & - & - & - & - & - & - & - & - & - & - \\
\hline LR3043/50 & 2.7 & $6.8 * 10^{-4}$ & $1.7 * 10^{-15}$ & $121 \pm 4$ & 181.5 & 0.081 & 2.00 & 14.8 & 582 & 1.0 & 1.0 \\
\hline $10 \mathrm{phr}$ & 3.4 & $5.2 * 10^{-4}$ & $1.3 * 10^{-15}$ & $141 \pm 6$ & 164.1 & 0.105 & 1.88 & 12.1 & 646 & 1.8 & 1.4 \\
\hline $20 \mathrm{phr}$ & 3.9 & $4.7 * 10^{-4}$ & $6.2 * 10^{-16}$ & $151 \pm 4$ & 146.7 & 0.114 & 1.80 & 10.8 & 700 & 2.5 & 1.8 \\
\hline $30 \mathrm{phr}$ & 4.4 & $6.7 * 10^{-4}$ & $3.2 * 10^{-15}$ & $130 \pm 5$ & 137.5 & 0.100 & 1.35 & 8.14 & 781 & 2.8 & 2.3 \\
\hline $40 \mathrm{phr}$ & 4.8 & $1.0 * 10^{-3}$ & $1.5^{*} 10^{-15}$ & $118 \pm 4$ & 110.9 & 0.161 & 1.30 & 5.94 & 599 & 2.6 & 1.3 \\
\hline $70 \mathrm{phr}$ & 4.9 & $4.3 * 10^{-4}$ & $1.1 * 10^{-15}$ & $100 \pm 4$ & 88.4 & 0.338 & 1.15 & 4.12 & 473 & 2.1 & 0.5 \\
\hline $100 \mathrm{phr}$ & 5.5 & $4.4 * 10^{-4}$ & $2.8 * 10^{-15}$ & $88 \pm 4$ & 65.4 & 0.449 & 0.75 & 1.35 & 269 & 2.9 & 0.5 \\
\hline $\begin{array}{c}100 \mathrm{phr}+ \\
\text { Belsil resin }\end{array}$ & 5.1 & $1.1 * 10^{-3}$ & $2.0 * 10^{-14}$ & $82 \pm 4$ & 68.5 & 0.205 & 0.85 & 1.95 & 340 & 2.0 & 0.8 \\
\hline $\begin{array}{c}30 \mathrm{phr} \\
\mathrm{TiO} 2(1)\end{array}$ & 3.4 & $1.1 * 10^{-2}$ & $9.9 * 10^{-14}$ & $98 \pm 4$ & 280.5 & 0.087 & 3.65 & 5.55 & 533 & 0.5 & 0.4 \\
\hline $\begin{array}{l}30 \mathrm{phr}+30 \\
\mathrm{phr} \mathrm{TiO} 2(1)\end{array}$ & 4.5 & $2.2 * 10^{-3}$ & $2.8 * 10^{-14}$ & $109 \pm 5$ & 234.7 & 0.248 & 3.30 & 7.03 & 643 & 0.8 & 0.3 \\
\hline $\begin{array}{c}30 \mathrm{phr} \\
\mathrm{TiO} 2(2)\end{array}$ & 4.3 & $4.5^{*} 10^{-2}$ & $5.4 * 10^{-13}$ & $110 \pm 4$ & 241.4 & 0.078 & 3.40 & 6.11 & 599 & 0.8 & 0.8 \\
\hline $\begin{array}{l}30 \mathrm{phr}+30 \\
\mathrm{phr} \mathrm{TiO} 2(2)\end{array}$ & 4.9 & $1.3 * 10^{-2}$ & $2.5^{*} 10^{-13}$ & $125 \pm 6$ & 223.9 & 0.156 & 3.10 & 6.77 & 682 & 1.3 & 0.7 \\
\hline
\end{tabular}

\subsection{Samples with $\mathrm{TiO}_{2}$}

In an attempt to further improve the properties of chloropropyl-functional silicone oil-filled elastomers, the $30 \mathrm{phr}$ sample, which showed - based on the figure of merit calculations - the most promising overall properties for DEs, was reinforced with Belsil resin to further improve viscous loss and immobilise the silicone oil. Additionally, $\mathrm{TiO}_{2}$ was added to this formulation, in order to increase permittivity and thereby also possible actuation strain. $\mathrm{TiO}_{2}$ is a commonly applied permittivity enhancer in silicone DEs [11-13,40] mainly due to great compatibility with the silicone matrix from the silicone-compatibilised surface treatments of the particles. Therefore, it was desired to investigate possible synergistic (or other positive) effects from the combination of chloropropyl-functional silicone oil and $\mathrm{TiO}_{2}$ since the chloropropyl-functional silicone oil in itself does not contribute with as significant dielectric permittivity enhancement as required for commercial products to become more competitive. The results of the addition of permittivity-enhancing $\mathrm{TiO}_{2}$ as well as Belsil resin are shown in Figure 11 to Figure 14. Two different kinds of $\mathrm{TiO}_{2}$ from Sachtleben were tested, namely R 420, which is rutile titanium dioxide (particle size $\sim 200 \mathrm{~nm}$ ), and Hombitec RM 130F rutile titanium dioxide (particle size $\sim 15 \mathrm{~nm}$ ). Two reference samples, prepared with $\mathrm{LR3043/50}$ and $\mathrm{TiO}_{2}$ without LMS-152, were also formulated. The sample compositions are shown in Table 1. The major difference between the two kinds of $\mathrm{TiO}_{2}$ is their particle size. Small $\mathrm{TiO}_{2}$ particle sizes can lead to better material properties but they also create 
a larger particle surface area within the elastomer, and this can lead to increased dielectric losses due to increased surface polarisation under an applied field.

The dispersion of $\mathrm{TiO}_{2}$ particles in the silicone matrix was investigated by SEM and SEM coupled with energy dispersive X-ray (EDX) spectroscopy. The resulting images are presented in supporting information and show a high level of dispersion of the $\mathrm{TiO}_{2}$ particles. The addition of LMS-152 is seen to increase the dispersion level of $\mathrm{TiO}_{2}$ in the samples. The EDX images in particular demonstrate the presence of the element Ti welldispersed throughout the samples.

The obtained storage moduli and viscous losses $\left(\tan \delta_{\text {visc }}\right)$ from rheological measurements of the samples with $\mathrm{TiO}_{2}$ are shown in Figure 11 and summarised in Table 3. From the rheological data it can be seen that the storage moduli increase substantially as a result of adding $\mathrm{TiO}_{2}$ and the films have become significantly stiffer - irrespective of the type of $\mathrm{TiO}_{2}$ used. Furthermore, viscous losses have increased somewhat in line with the addition of the $\mathrm{TiO}_{2}$ particles compared to the sample with only $30 \mathrm{phr}$ LMS-152. Viscous losses are also higher than for the samples prepared with only $\mathrm{TiO}_{2}$. Thus, there seems to be a combination effect when combining LMS-152 and $\mathrm{TiO}_{2}$ in the elastomer, due to the very high concentration of added filler/plasticiser in the network. Lower concentrations (5-25 phr) of $\mathrm{TiO}_{2}$ also have similar effects on viscous loss.

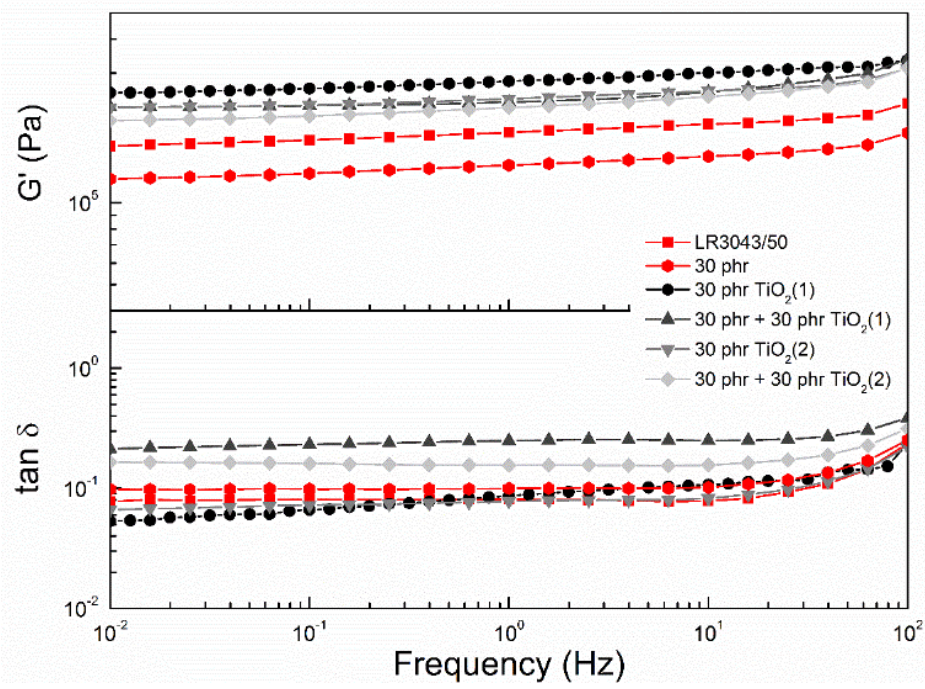

Figure 11. Storage moduli $\left(G^{\prime}\right)$ and viscous loss $\left(\tan \delta_{\text {visc }}\right)$ as functions of frequency for elastomers prepared with chloropropyl-functional silicone oil and two different kinds of $\mathrm{TiO}_{2}$.

The Young's moduli (determined at 5\% strain, which are shown in Table 3) also illustrate that the elastomers soften after adding silicone oil and that $\mathrm{TiO}_{2}$ particles significantly stiffen the network in the low-strain regime. At larger strains all composite elastomers behave very similarly and more or less fall together on a universal curve. The stress-strain curves presented in Figure 12 reveal that samples containing $\mathrm{TiO}_{2}$ have become weaker, as the maximum stresses are significantly reduced. This is probably due to the high loading of fillers, which increases the chances of mechanical defects in elastomers with $\mathrm{TiO}_{2}$. 


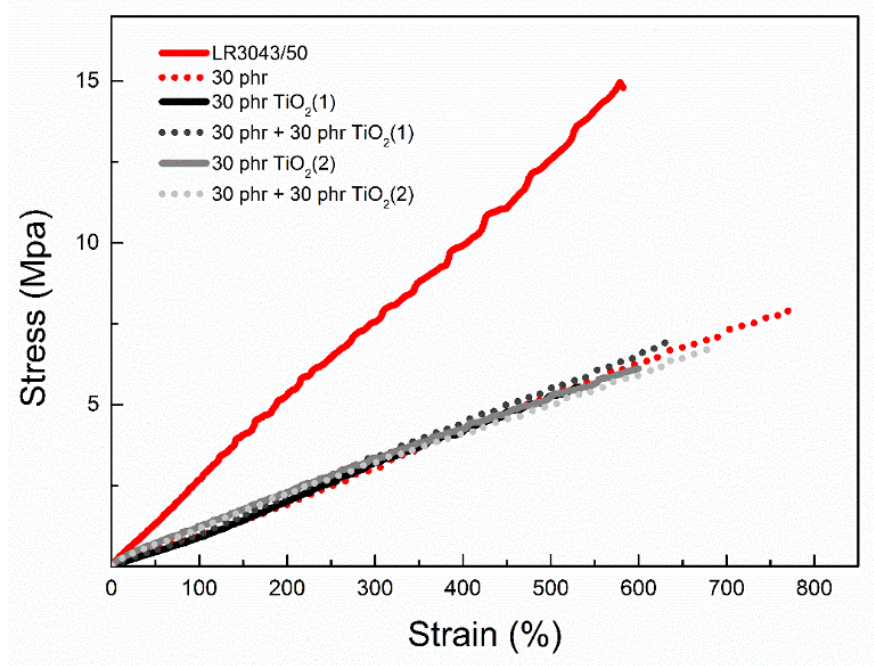

Figure 12. Stress-strain curves for elastomers prepared with chloropropyl-functional LMS-152 and two different kinds of $\mathrm{TiO}_{2}$.

The influence of the two different kinds of $\mathrm{TiO}_{2}$ on the dielectric properties of LR3043/50 elastomers is shown in Figure 13, while the data are summarised in Table 3. From Figure 13 and Table 3 it can be seen that the addition of $30 \mathrm{phr}$ R420 $\mathrm{TiO}_{2}\left(\mathrm{TiO}_{2}(1)\right)$ to the commercial elastomer LR3043/50 increases permittivity from $\varepsilon^{\prime}=2.7$ to $\varepsilon^{\prime}=3.4$ at $100 \mathrm{~Hz}$, whereas the addition of identical amounts of $\mathrm{TiO}_{2}(2)$ increases the permittivity of LR3043/50 to $\varepsilon^{\prime}=4.3$ at $100 \mathrm{~Hz}$. Consequently, there is a large difference in how much the two kinds of $\mathrm{TiO}_{2}$ increase permittivity. Furthermore, dielectric loss increases significantly with the addition of both types of $\mathrm{TiO}_{2}$, whereby Hombitec $\left(\mathrm{TiO}_{2}(2)\right)$ increases dielectric loss the most. This difference in permittivity and loss is due to the difference in size between the two types of $\mathrm{TiO}_{2}$, i.e. smaller $\mathrm{TiO}_{2}$ particles create an elastomer with more particles and a larger total particle surface area than larger particles at the same concentration. This leads to larger interface dipole layers in the elastomer, and thereby larger permittivity, as well as the greater chance of increased dielectric losses from surface polarisation and dipole relaxation mechanisms.

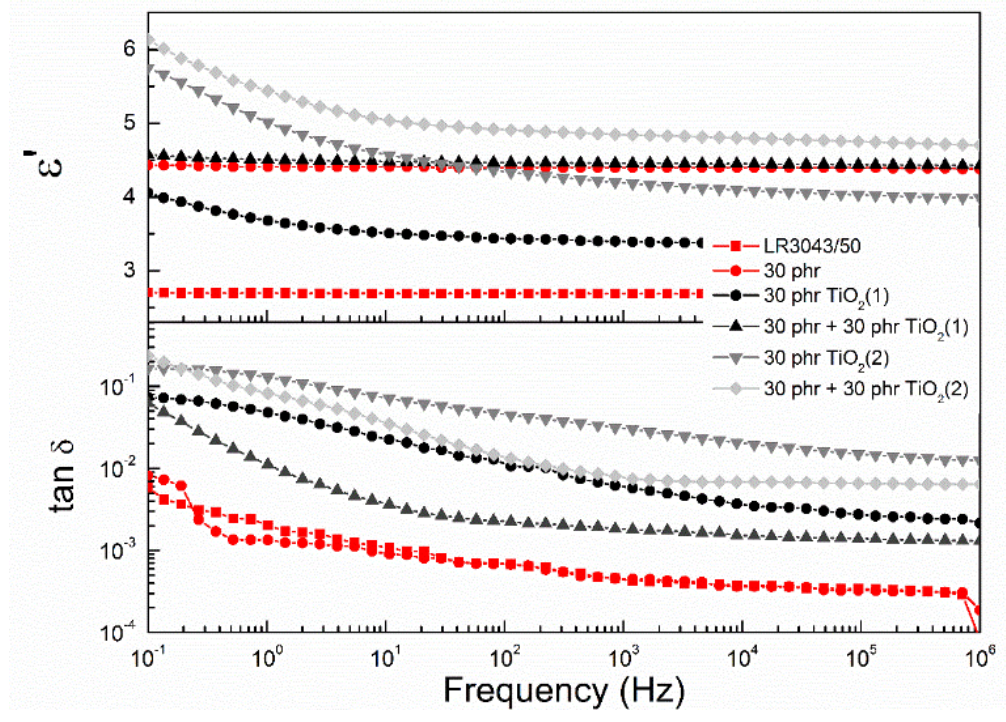

Figure 13. Dielectric permittivity $\left(\varepsilon^{\prime}\right)$ and loss tangent $(\tan \delta)$ as functions of frequency for elastomers prepared with chloropropyl-functional silicone oil and two different kinds of $\mathrm{TiO}_{2}$. 
The addition of $\mathrm{TiO}_{2}$ to the elastomer with $30 \mathrm{phr}$ silicone oil increases permittivity somewhat, albeit not as much as expected. $\mathrm{R} 420 \mathrm{TiO}_{2}\left(\mathrm{TiO}_{2}(1)\right)$ increases permittivity from $\varepsilon^{\prime}=4.4$ for the sample with only $30 \mathrm{phr}$ LMS-152 to $\varepsilon^{\prime}=4.5$ for the sample with $30 \mathrm{phr}$ LMS-152 plus $30 \mathrm{phr} \mathrm{R} 420 \mathrm{TiO}_{2}$, whereas $30 \mathrm{phr}$ Hombitec $\mathrm{TiO}_{2}\left(\mathrm{TiO}_{2}(2)\right)$ increases permittivity to $\varepsilon^{\prime}=4.9$. The dielectric losses of samples containing both LMS-152 and $\mathrm{TiO}_{2}$ are lower than those containing only $\mathrm{TiO}_{2}$. This again indicates that the addition of LMS-152 lowers the dielectric losses of silicone DEs, or, put in a different way, LMS-152 does not contribute any loss, even though it contributes large dielectric permittivity. At high frequencies LMS-152 decreases dielectric loss ( $\tan$ $\delta$ ) by a factor of $\sim 2$. At intermediate frequencies the reduction is even greater (up to almost a factor of ten). At the lowest applied frequencies, however, the reducing effect does disappear for both kinds of $\mathrm{TiO}_{2}$.

Conductivity as a function of the frequency of samples prepared with $\mathrm{TiO}_{2}$ is shown in Figure 14 and summarised in Table 3. Conductivity is seen to increase with the addition of $\mathrm{TiO}_{2}$, to which $\mathrm{Hombitec}^{\mathrm{TiO}}{ }_{2}$ $\left(\mathrm{TiO}_{2}(2)\right)$ contributes the most. The values, however, are still so low that they are negligible and conductivity remains dependent of frequency in the entire frequency region, meaning that no conducting paths are created in the material [41]. Furthermore, it is evident that the samples prepared with $30 \mathrm{phr} \mathrm{LMS}-152$ and $30 \mathrm{phr} \mathrm{TiO}_{2}$ exhibit lower conductivity than the samples with only $\mathrm{TiO}_{2}$ and no LMS-152.

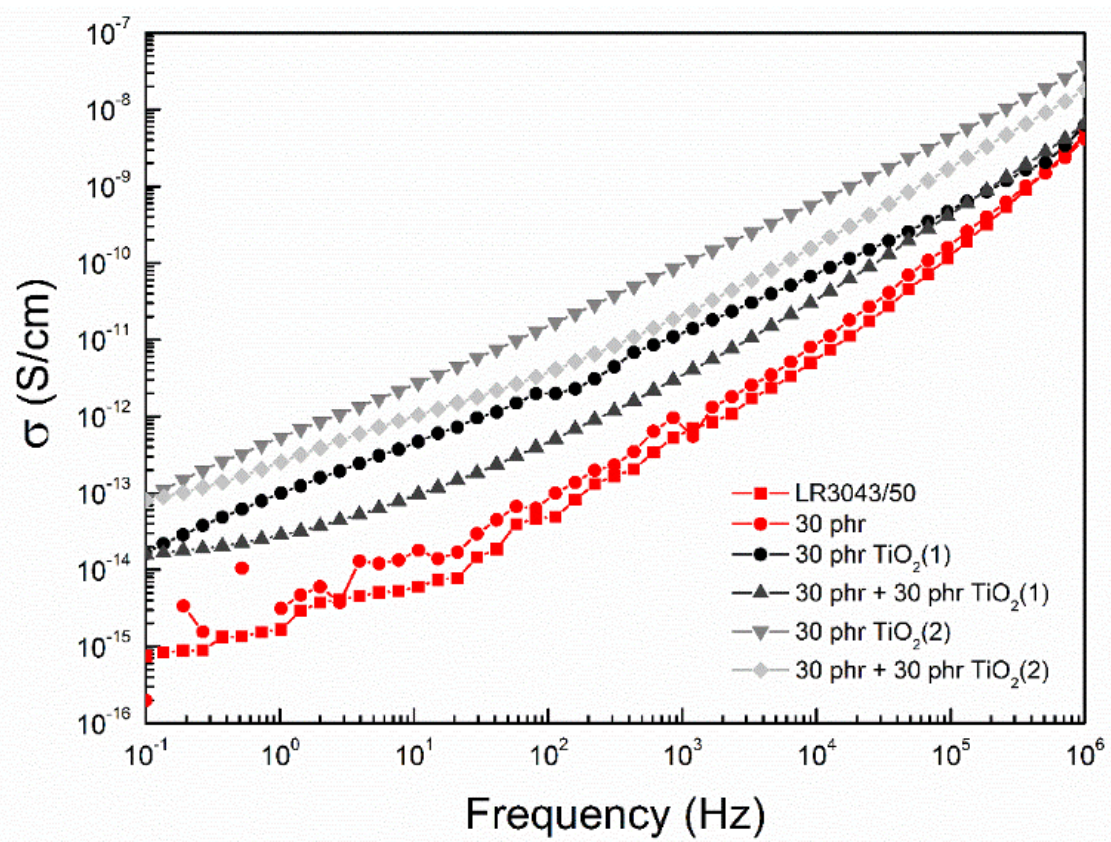

Figure 14. Conductivity as a function of frequency for elastomers prepared with chloropropyl-functional silicone oil and two different kinds of $\mathrm{TiO}_{2}$.

The dielectric breakdown strengths of samples prepared with $\mathrm{TiO}_{2}$ are presented in Table 3. It is notable that samples prepared with both kinds of $\mathrm{TiO}_{2}$ have lower breakdown strengths than neat $\mathrm{LR} 3043 / 50$. For TiO2(1) ( $\mathrm{R}$ 420) breakdown strength has dropped from $121.0 \mathrm{~V} / \mu \mathrm{m}$ for $\mathrm{LR} 3043 / 50$ to $97.8 \mathrm{~V} / \mu \mathrm{m}$, while for $\mathrm{TiO}_{2}(2)$ (Hombitec) it has decreased to $110 \mathrm{~V} / \mu \mathrm{m}$ - a smaller but still remarkable decrease. This decrease in the breakdown of filled elastomers is well-known and could be due to an increased number of defects, either on the particle surface or around the particles as well as increased dielectric losses. Furthermore, particle agglomeration can lead to localised areas with reduced breakdown strengths [36]. For both types of $\mathrm{TiO}_{2}$ it can be seen that upon the addition of $30 \mathrm{phr}$ LMS-152 breakdown strength increases by over $10 \%$. This means that adding LMS-152 has a positive effect on dielectric breakdown strength, even though the materials become softer, possibly due to the higher mobility of the components within the reaction mixture during curing. Data for the Weibull analysis of electrical breakdown strengths are shown in Table 4. From the Weibull analysis it is evident that for both types of $\mathrm{TiO}_{2}$, initially, the addition of $\mathrm{TiO}_{2}$ to the composite decreases $\eta$ significantly 
( 20 and 10\%, respectively, for R 420 and Hombitec), albeit with a slight increase in $\beta$ for both samples. When the chloropropyl-functional silicone oil is added to the composites, $\eta$ increases $\sim 10 \%$ for both samples. Nevertheless, $\beta$ for both samples drops by a factor of almost two, which gives a clear indication of the heterogeneity of the samples with at least two types of particles (silica in the commercial LR elastomer and the added $\mathrm{TiO}_{2}$ ) as well as PDMS and silicone oil. This observation also agrees well with the unexpected increase in the viscous losses of these two types of composites.

Table 4. Weibull parameters for TiO2-filled samples as well as the correlation function between data and fit.

\begin{tabular}{|c|c|c|c|c|}
\hline $\begin{array}{l}\text { Film with } \\
\text { entry }\end{array}$ & $\begin{array}{c}\text { Number of } \\
\text { measurements }\end{array}$ & $\begin{array}{c}\text { Scale } \\
\text { parameter } \eta \\
{[\mathrm{V} / \mu \mathrm{m}]}\end{array}$ & $\begin{array}{c}\text { Shape } \\
\text { parameter } \beta\end{array}$ & $r^{2}$ \\
\hline $\begin{array}{c}30 \mathrm{phr} \\
\mathrm{TiO}_{2}(1)\end{array}$ & 10 & 100 & 29 & 0.94 \\
\hline $\begin{array}{l}30 \mathrm{phr}+30 \\
\text { phr } \mathrm{TiO}_{2}(1)\end{array}$ & 10 & 111 & 25 & 0.89 \\
\hline $\begin{array}{c}30 \mathrm{phr} \\
\mathrm{TiO}_{2}(2)\end{array}$ & 10 & 112 & 30 & 0.88 \\
\hline $\begin{array}{l}30 \mathrm{phr}+30 \\
\mathrm{phr} \mathrm{TiO}_{2}(2)\end{array}$ & 10 & 128 & 27 & 0.87 \\
\hline
\end{tabular}

The figure of merit calculations (calculated using $Y$ ) for $\mathrm{TiO}_{2}$-filled samples can be seen in Table 3, whereby it is evident that it is only the sample prepared with $30 \mathrm{phr} \mathrm{LMS}-152$ and $30 \mathrm{phr} \mathrm{Hombitec} \mathrm{TiO}_{2}\left(\mathrm{TiO}_{2}(2)\right)$ that induces an improvement in the combined properties compared to LR3043/50. However, when viscous losses are taken into account in the adjusted figure of merit calculations, none of the samples with $\mathrm{TiO}_{2}$ performs better than neat LR3043/50. Additionally, if the dielectric losses of $\mathrm{TiO}_{2}$-containing samples were taken into account in the adjusted figure of merit calculations, LR3043/50 with only chloropropyl-functional oil would be favoured even more than $\mathrm{TiO}_{2}$-containing samples.

\subsection{Electromechanical properties}

The electromechanical behaviour of the sample with the best predicted performance based on figure of merit calculations (LR3043/50 + 30 phr LMS-152) was investigated in circular strain tests to compare with the reference material. The measured actuation strains are shown in Figure 15. It is clear from Figure 15 that the sample with $30 \mathrm{phr}$ LMS-152 has a greater strain response than pure LR3043/50 at any given electrical field reaching an actuation strain of $19 \%$ at $210 \mathrm{~V} / \mu \mathrm{m}$ while pure LR3043/50 shows an actuation strain of $6 \%$ at the same field. This increase fits closely with that predicted from the figure of merit calculations. 


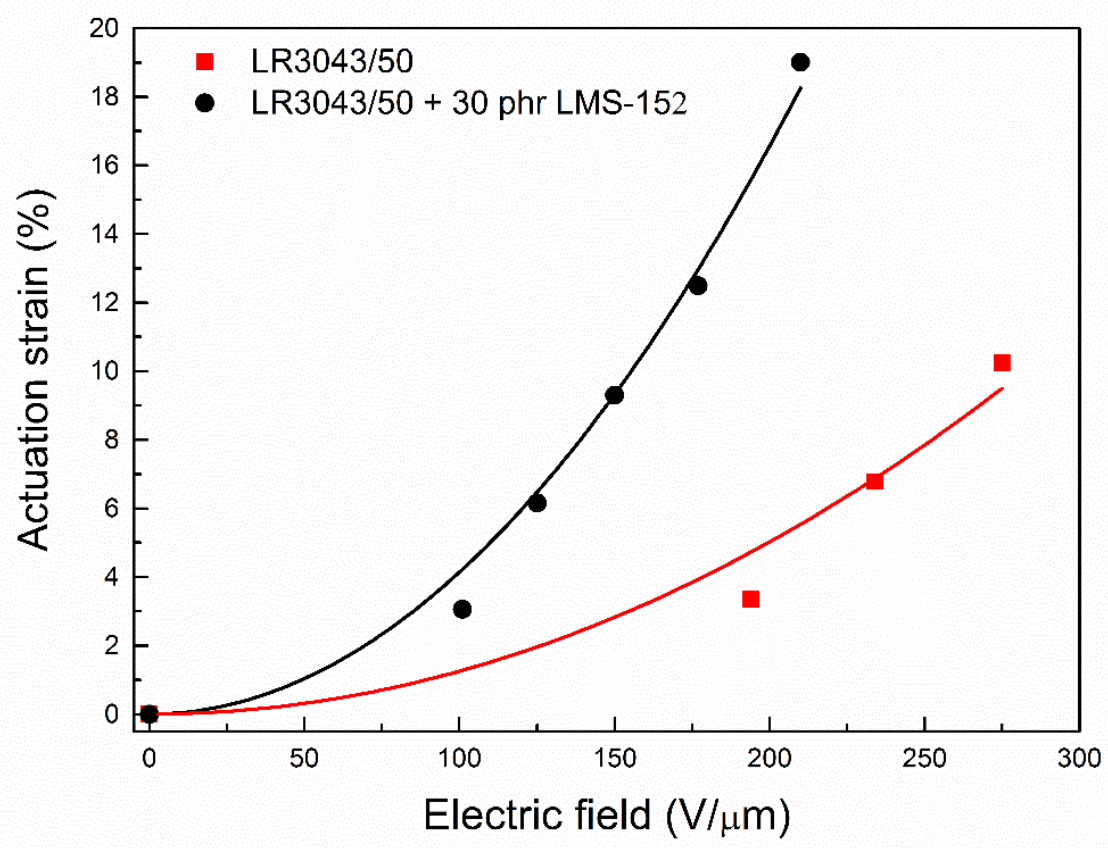

Figure 15. Actuation strain of pure LR3043/50 compared with actuation strain of LR3043/50 with $30 \mathrm{phr}$ LMS-152 as functions of applied electrical field.

Furthermore, we are currently investigating the lifetime of these chloropropyl-functional silicone oil-filled materials. This is a commonly non-addressed parameter of DEs, since research usually focuses mainly on maximum achievable strains in initial actuation cycles.

\section{Conclusions}

A new simple method of creating softer silicone dielectric elastomers with high dielectric permittivity has been developed through the use of chloropropyl-functional siloxanes. The study opens up the possibility of creating silicone dielectric elastomers with reduced dielectric losses, and thereby it turns the emphasis of material optimisation away from focusing solely on increased actuation strain and instead on the very important field of dielectric elastomer losses. The method is based on adding commercially available chloropropyl-functional silicone oil to a tough commercial LSR silicone elastomer, following which the elastomer becomes increasingly softer as more silicone oil is added. Viscous losses are not influenced significantly up to a certain concentration of LMS-152, above which they increase, due to increasing amounts of non-bonded structures in the elastomer. Dielectric breakdown strength has been found to increase in the presence of low amounts of added silicone oil, whereas it decreases with larger amounts. Dielectric permittivity increases greatly at high concentrations of silicone oil and attains a two-fold increase compared to the pristine commercial LSR silicone. Remarkably, dielectric losses reduce at low concentrations of chloropropyl-functional silicone oil, and the silicone oil is also able to lower the dielectric losses of $\mathrm{TiO}_{2}$-filled elastomers. Overall, it is clear from this work that emphasis should be placed on the optimal concentration of high permittivity fillers in dielectric elastomers. In this case the optimal concentration has been found through figure of merit calculations, while dielectric elastomer properties are optimal at a concentration of $30 \mathrm{phr}$ chloropropyl-functional silicone oil, where high permittivity is matched with high breakdown strength and low dielectric and viscous losses.

\section{Acknowledgements}

The authors gratefully acknowledge the financial support of the Danish Council for Independent Research and Innovationsfonden Denmark. 


\section{References}

[1] Pelrine R E, Kornbluh R D and Joseph J P 1998 Electrostriction of polymer dielectrics with compliant electrodes as a means of actuation Sensors Actuators A Phys. 64 77-85

[2] Pelrine R, Kornbluh R, Pei Q and Joseph J 2000 High-speed electrically actuated elastomers with strain greater than $100 \%$ Science 287 836-9

[3] Balakrisnan B, Nacev A, Burke J M, Dasgupta A and Smela E 2012 Design of compliant meanders for applications in MEMS, actuators, and flexible electronics Smart Mater. Struct. 21075033

[4] Madsen F B, Dimitrov I, Daugaard A E, Hvilsted S and Skov A L 2013 Novel cross-linkers for PDMS networks for controlled and well distributed grafting of functionalities by click chemistry Polym. Chem. 4 1700-7

[5] Madsen F B, Daugaard A E, Hvilsted S, Benslimane M Y and Skov A L 2013 Dipolar cross-linkers for PDMS networks with enhanced dielectric permittivity and low dielectric loss Smart Mater. Struct. 22104002

[6] Zhang L, Wang D, Hu P, Zha J-W, You F, Li S-T and Dang Z-M 2015 Highly improved electroactuation of dielectric elastomers by molecular grafting of azobenzenes to silicon rubber J. Mater. Chem. C 3 4883-9

[7] Madsen F B, Yu L, Daugaard A E, Hvilsted S and Skov A L 2014 Silicone elastomers with high dielectric permittivity and high dielectric breakdown strength based on dipolar copolymers Polymer 55 6212-9

[8] Kussmaul B, Risse S, Kofod G, Waché R, Wegener M, McCarthy D N, Krüger H and Gerhard R 2011 Enhancement of dielectric permittivity and electromechanical response in silicone elastomers: molecular grafting of organic dipoles to the macromolecular network Adv. Funct. Mater. 21 4589-94

[9] Opris D M, Molberg M, Walder C, Ko Y S, Fischer B and Nüesch F A 2011 New silicone composites for dielectric elastomer actuator applications in competition with acrylic foil Adv. Funct. Mater. 21 3531-9

[10] Quinsaat J E Q, Alexandru M, Nueesch F A, Hofmann H, Borgschulte A and Opris D M 2015 Highly stretchable dielectric elastomer composites containing high volume fraction of silver nanoparticles $J$. Mater. Chem. A 3 14675-85

[11] Gallone G, Galantini F and Carpi F 2010 Perspectives for new dielectric elastomers with improved electromechanical actuation performance: composites versus blends Polym. Int. 59 400-6

[12] Ouyang G, Wang K and Chen X Y 2012 TiO2 nanoparticles modified polydimethylsiloxane with fast response time and increased dielectric constant J. Micromechanics Microengineering 22074002

[13] Stoyanov H, Brochu P, Niu X, Della Gaspera E and Pei Q 2012 Dielectric elastomer transducers with enhanced force output and work density Appl. Phys. Lett. 100262902 
[14] Romasanta L J, Leret P, Casaban L, Hernández M, de la Rubia M A, Fernández J F, Kenny J M, Lopez-Manchado M A and Verdejo R 2012 Towards materials with enhanced electro-mechanical response: CaCu3Ti4O12-polydimethylsiloxane composites J. Mater. Chem. 22 24705-12

[15] Zhao H, Wang D-R, Zha J-W, Zhao J and Dang Z-M 2013 Increased electroaction through a molecular flexibility tuning process in TiO2-polydimethylsilicone nanocomposites J. Mater. Chem. A $13140-5$

[16] Larsen A L, Sommer-Larsen P and Hassager O 2004 How to tune rubber elasticity Proc. SPIE 5385 $108-17$

[17] Bejenariu A G, Yu L and Skov A L 2012 Low moduli elastomers with low viscous dissipation Soft Matter 8 3917-23

[18] Madsen F B, Daugaard A E, Fleury C, Hvilsted S and Skov A L 2014 Visualisation and characterisation of heterogeneous bimodal PDMS networks RSC Adv. 4 6939-45

[19] Carpi F, Gallone G, Galantini F and De Rossi D 2008 Silicone-Poly(hexylthiophene) Blends as Elastomers with Enhanced Electromechanical Transduction Properties Adv. Funct. Mater. 18 235-41

[20] Liu H, Zhang L, Yang D, Ning N, Yu Y, Yao L, Yan B and Tian M 2012 A new kind of electroactive polymer composite composed of silicone elastomer and polyethylene glycol J. Phys. D. Appl. Phys. 45485303

[21] Razak A H A, Szabo P and Skov A L 2015 Enhancement of dielectric permittivity by incorporation of PDMS-PEG multi block copolymers in silicone elastomers RSC Adv. 5 53054-62

[22] Risse S, Kussmaul B, Krüger H and Kofod G 2012 Synergistic improvement of actuation properties with compatibilized high permittivity filler Adv. Funct. Mater. 22 3958-62

[23] Zakaria S, Morshuis P H F, Benslimane M Y, Yu L and Skov A L 2015 The electrical breakdown strength of prestretched elastomers with and without sample volume conservation Smart Mater. Struct. 2455009

[24] Gatti D, Haus H, Matysek M, Frohnapfel B, Tropea C and Schlaak H F 2014 The dielectric breakdown limit of silicone dielectric elastomer actuators Appl. Phys. Lett. 104052905

[25] Tröls A, Kogler A, Baumgartner R, Kaltseis R, Keplinger C, Schwödiauer R, Graz I and Bauer S 2013 Stretch dependence of the electrical breakdown strength and dielectric constant of dielectric elastomers Smart Mater. Struct. 22104012

[26] Zakaria S, Morshuis P H F, Benslimane M Y, Gernaey K V. and Skov A L 2014 The electrical breakdown of thin dielectric elastomers: thermal effects ed Y Bar-Cohen Proc. SPIE 9056 90562V

[27] Madsen F B, Javakhishvili I, Jensen R E, Daugaard A E, Hvilsted S and Skov A L 2014 Synthesis of telechelic vinyl/allyl functional siloxane copolymers with structural control Polym. Chem. 5 7054-61

[28] Madsen F B, Yu L, Daugaard A E, Hvilsted S and Skov A L 2015 A new soft dielectric silicone elastomer matrix with high mechanical integrity and low losses RSC Adv. 5 10254-9 
[29] Brook M A, Saier H, Schnabel J, Town K and Maloney M 2007 Pretreatment of Liquid Silicone Rubbers to Remove Volatile Siloxanes 8796-805

[30] Delebecq E and Ganachaud F 2012 Looking over liquid silicone rubbers: (1) network topology vs chemical formulations ACS Appl. Mater. Interfaces 4 3340-52

[31] Delebecq E, Hermeline N, Flers A and Ganachaud F 2012 Looking over Liquid Silicone Rubbers: (2) Mechanical Properties vs Network Topology ACS Appl. Mater. Interfaces 4 3353-63

[32] Lichtenecker K 1926 Dielectric constants of natural and artificial mixtures Phys. Zeitschrift $27115-$ 58

[33] Maxwell J C 1892 Electricity and Magnetism (Clarendon Press, Oxford)

[34] Wagner K W 1924 Die Isolierstoffe der Elektrotechnik (Springer, Berlin)

[35] Lichtenecker K and Rother K 1931 Die Herleitung des logarithmischen Mischungsgesetzes aus allgemeinen Prinzipien der stationären Strömung Phys. Zeitschrift 32 255-160

[36] Vudayagiri S, Zakaria S, Yu L, Hassouneh S S, Benslimane M and Skov A L 2014 High breakdownstrength composites from liquid silicone rubbers Smart Mater. Struct. 23105017

[37] Kollosche M, Stoyanov H, Ragusch H, Risse S, Becker a. and Kofod G 2010 Electrical breakdown in soft elastomers: Stiffness dependence in un-pre-stretched elastomers 2010 10th IEEE Int. Conf. Solid Dielectr. 1-4

[38] Sommer-Larsen P and Larsen A L 2004 Materials for dielectric elastomer actuators ed Y Bar-Cohen Proc. SPIE 5385 68-77

[39] Yu L, Madsen F B, Hvilsted S and Skov A L 2015 Dielectric elastomers, with very high dielectric permittivity, based on silicone and ionic interpenetrating networks RSC Adv. 5 49739-47

[40] Carpi F and De Rossi D 2005 Improvement of Electromechanical Actuating Performances of a Silicone Dielectric Elastomer by Dispersion of Titanium Dioxide Powder IEEE Trans. Dielectr. Electr. Insul. 12 835-43

[41] Connor M T, Roy S, Ezquerra T A and Baltá Calleja F J 1998 Broadband ac conductivity of conductor-polymer composites Phys. Rev. B 57 2286-94 